\title{
AVALIAÇÃO DA SUSTENTABILIDADE DE HABITAÇÃO DE INTERESSE SOCIAL (HIS) ATRAVÉS DA METODOLOGIA MASP-HIS.
}

\author{
Eliká Deboni Ceolin, Especialista (IMED); \\ Lisiane Ilha Librelotto, Dra. Eng. (UFSC).
}

\author{
PALAVRAS CHAVE \\ HIS; sustentabilidade; avaliação.
}

KEYWORDS:

Social house; sustainability; evaluation

\section{RESUMO}

Vários métodos foram desenvolvidos para avaliar projetos e construções sustentáveis. Apesar de existirem iniciativas de selos, etiquetagem, certificações e metodologias de avaliação da sustentabilidade, os critérios adotados priorizam muitas vezes os aspectos ambientais deixando em segundo plano as demais dimensões da sustentabilidade: social e econômica. Em países em desenvolvimento, especialmente, os aspectos econômicos e sociais deveriam ter um destaque maior, uma vez que tem grande impacto na sustentabilidade global. Este trabalho utiliza uma metodologia integrada de avaliação da sustentabilidade no projeto para Habitação de Interesse Social desenvolvida no Brasil, a metodologia MASP-HIS (CARVALHO, 2009). Os resultados alcançados demonstraram que o projeto, mesmo antes dos selos nacionais serem lançados, atende a maioria dos requisitos do método em questão.

\begin{abstract}
Many methods aim to evaluate projects and buildings in order to reduce its environmental impacts. Although there are initiatives like labelling, certification and assessment methodologies this sustainability criteria prioritize environmental issues often not contemplating the other dimensions of sustainability: social and economic. In emerging countries, especially the economic and social aspects should be given more attention, since it has greater impact on global sustainability. This paper applies an integrated assessment methodology in a social house developed in Brazil using MASP-HIS methodology. The first results founded shows that, even before national certifications, this project succeed in most of MASP-HIS requirements.
\end{abstract}




\section{INTRODUÇÃO}

A avaliação da sustentabilidade das edificações é realizada através de selos, certificações, etiquetas e guias. Atualmente alguns países já incorporaram os selos de avaliação de edificações à legislação. Na Europa os selos já fazem parte da legislação nacional em alguns países, como é o caso do Building Research Establishment Environmental Assessment Method (Breeam), na Inglaterra, criado na década de 1990.

Não é possível copiar os métodos devido ao sucesso em outros países, pois inúmeros critérios perdem a validade e alguns itens não considerados em sistemas internacionais são de suma importância para o País (SILVA, 2000).

Os selos podem ser divididos em duas categorias segundo Silva \& Agopyan (2004): sistemas orientados para o mercado e sistemas de avaliação orientados para pesquisa. O primeiro foi projetado para ser facilmente absorvido por profissionais da área e tem grande uso como marketing das edificações. $O$ segundo, por sua vez, tem forte ênfase na fundamentação científica e visa o desenvolvimento de novos sistemas.

No Brasil, as certificações foram inicialmente importações de modelos estrangeiros, o internacionalmente reconhecido Leadership in Energy and Environmental Design (LEED), é um exemplo. Atualmente existem no País diversas iniciativas para criação de selos nacionais, estudos e pesquisas. Estas últimas são desenvolvidas com o intuito de estabelecer sistemas de avaliação específicos para a realidade brasileira.

As certificações como AQUA (Alta Qualidade Ambiental), selo Procel Edifica, e o mais recente Selo Azul da Caixa Econômica Federal são exemplos de avaliações criadas com base nas características sociais, econômicas e ambientais nacionais, ou, então, adaptadas ao contexto nacional. O Selo Azul, por exemplo, é uma ferramenta gratuita para avaliação da sustentabilidade de projeto e traz critérios diferenciados como o maior peso do aspecto social da sustentabilidade e a consideração da matriz renovável de energia elétrica brasileira.

\section{MASP-HIS}

As ferramentas que avaliam a sustentabilidade nos selos serviram de apoio para a criação da Metodologia de Avaliação de Sustentabilidade em Projeto para Habitações de Interesse Social (MASP-HIS) criada por Carvalho, (2009). O projeto e aborda as três esferas da sustentabilidade: econômica, social e ambiental. Em cada categoria são avaliados os projetos e os subsistemas construtivos através de questionários e fórmulas. Para a avaliação utiliza-se um software com base no Excel (Microsoft Excel) denominado "Pro-MASP-HIS" (CARVALHO, 2009), os componentes do selo estão detalhados no esquema da Figura 1.

Carvalho (2009) define seis etapas para avaliação: três etapas de avaliação de projeto quanto às dimensões econômicas, ambientais e socioculturais e três etapas de análise das categorias e subcategorias. As categorias são avaliadas também sob o enfoque das três dimensões da sustentabilidade e são divididas em sete subsistemas: estrutura, cobertura, instalações, tratamento, pintura, vedações horizontais e vedações verticais. Sendo que este último, vedações verticais, foi o escolhido para detaIhamento do modelo devido ao grande impacto que tem em uma edificação em relação aos custos, patologias e desempenho da edificação.

O MASP-HIS tem como objetivo proporcionar a avaliação na fase de projeto do ciclo de vida da edificação com foco na sustentabilidade. Pretende, desta forma, medir os possíveis impactos e procura assegurar a qualidade através da gestão dos aspectos

Permite, ainda, a comparação entre subsistemas para definição da alternativa construtiva mais sustentável. Hoffman (2013) realizou a adaptação do MASP-HIS de forma a propiciar a avaliação da sustentabilidade nas habitações considerando a diferenciação dos materiais empregados.aplicação de recursos naturais trará menor impacto ambiental nas fases de uso e descarte dessa edificação.

\subsection{APLICAÇÃO}

O método é aplicado com a utilização do PROMAS

Figura 02 - Equações MASP-HIS.
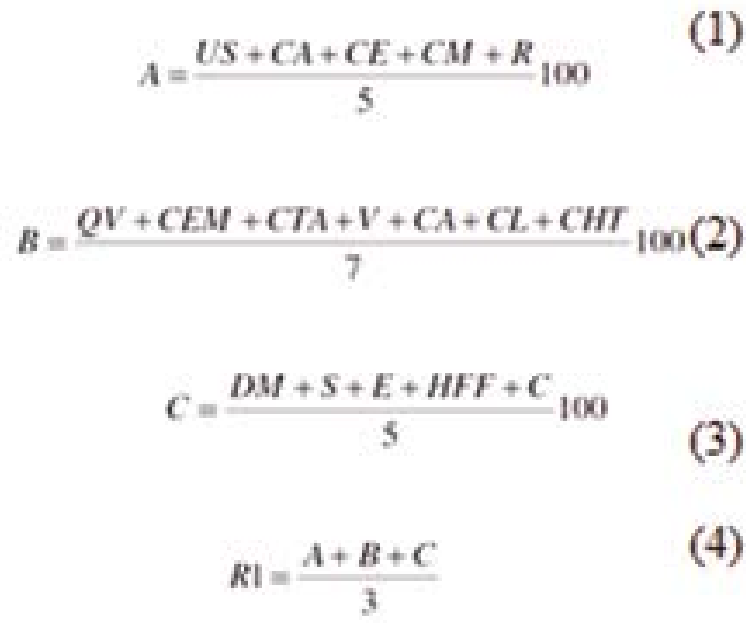
Figura 01: Esquema MASP-HIS



P-HIS, onde são respondidas questões com respos-

Fonte: Autores tas sim, não e não se aplica (n.a.) dos quais se obtêm os índices parciais de projeto e após é realizada a análise dos subsistemas. Na metodologia foi proposto o sistema de vedações verticais que é o avaliado neste estudo. O objetivo é atingir um valor superior a 50 na soma das respostas. $\mathrm{O}$ resultado para cada aspecto é uma média ponderada das questões de cada categoria, conforme as equações (1), (2), (3) e (4).

Toma-se como exemplo o aspecto ambiental, a equação (1) corresponde à média da categoria "Consumo de recursos, energia e fluxo de massa", composta por cinco subcategorias, a equação (2) corresponde à média da categoria "Qualidade interna da habitação - conforto e saúde" com sete subcategorias, a equação (3) corresponde à média das cinco subcategorias da categoria "Qualidade do produto, habitação" e, por último, a equação (4) corresponde ao Índice de sustentabilidade parcial do aspecto cultural para os projetos completos. Da mesma forma ocorre nos outros dois aspectos: econômico e sociocultural.

O método MASP-HIS traz o detalhamento para aplicação da avaliação de subsistema o que avalia as vedações verticais. Carvalho (2009) justifica a escolha de acordo com alguns critérios, dentre eles por as vedações verticais serem uma das maiores categorias, por terem um grande 


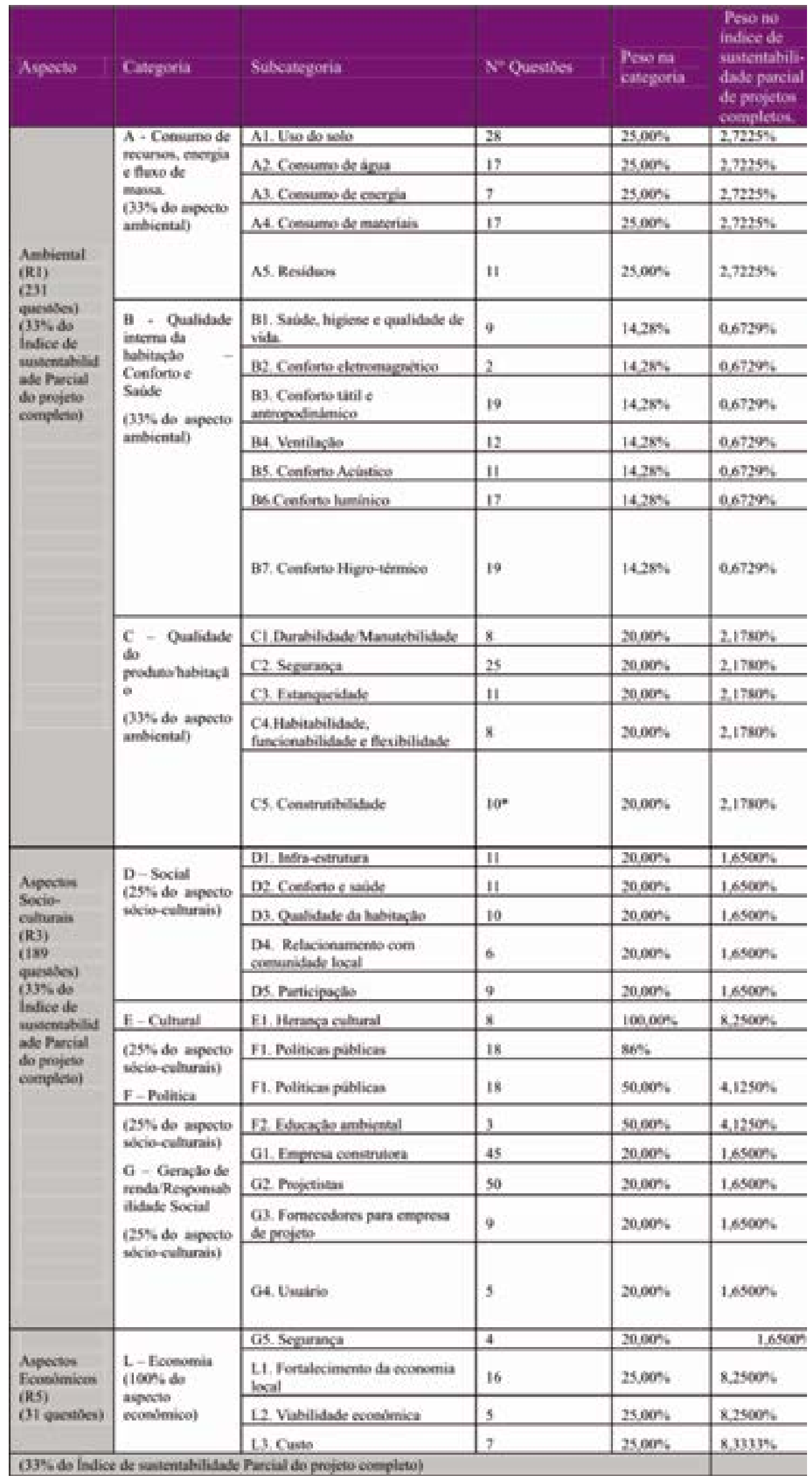

Figura 3 - Planilha de quantidade de questões 


\section{CASA ALVORADA}

A casa alvorada é um protótipo resultante de um projeto de pesquisa desenvolvido da Universidade Federal do Rio Grande do Sul, pelo grupo de pesquisa NORIE, sob a coordenação do professor Dr. Miguel Aloysio Sattler. O projeto se desenvolveu em dezembro de 1997, o estudo contemplou além de uma unidade habitacional o tratamento do lote, paisagismo e abordou também o suporte ao conforto ambiental, gestão de resíduos, água e recursos energéticos.

O município de Alvorada fica na região metropolitana de Porto Alegre- RS e tem como característica ser uma "cidade-dormitório" (SATTLER, 2007). Para casa foi definido um programa de necessidades de $48,50 \mathrm{~m}^{2}$ de área construída, dois dormitórios, banheiro, hall, sala e cozinha integradas e área de serviço, como pode ser visto na Figura 4. Foi considerada a previsão de ampliação da residência.

O projeto previu técnicas passivas de controle ambiental o que determinou grande parte do partido arquitetônico. Além disto, foi previsto reaproveitamento de água da chuva e tratamento de esgoto doméstico e maior aproveitamento da energia solar, conforme pode ser visto na Figura 5. Os materiais utilizados na construção foram definidos a partir de um estudo sobre as construções existentes no município de Alvorada. Os princípios para escolha de materiais foram baseados nos pré-requisitos de Sperb, Bonin e Sattler (1998) apud Satler (2007), são eles:

- Pequenas distâncias de transporte;

- Baixo conteúdo energético;

- Elevado grau de renovabilidade ou reciclabilidade; A adoção dos materiais utilizados considerou a produção regional, a cultura local de construção, o clima, a qualificação da mão de obra e a redução de consumo de materiais inadequados ambientalmente. Foram utilizadas paredes de alvenaria de tijolos cerâmicos maciços, estrutura em concreto armado, telhas cerâmicas com estrutura em madeira, chapa de alumínio (reaproveitamento de offset de gráficas) e forro de madeira, porém, em itálico.

O protótipo foi construído no campus do Vale da UFRGS e em 2000 foi implantado na cidade de Nova Hartz, também na zona metropolitana da capital gaúcha. Na implantação final algumas etapas da construção não foram realizadas de acordo com o projeto original e especificações foram substituídas, uma vez que se tratava de convênio firmado com a Prefeitura Municipal de Nova Hartz. Contudo, o MASP-HIS é um método de avaliação de projeto, portanto para a avaliação foram consideradas as especificações do projeto original oriundo da pesquisa do NORIE/UFRGS.

\section{RESULTADOS}

A resposta dos questionários foi feita de acordo com as informações constantes no livro Habitare, "Habitações de baixo custo mais sustentáveis: a casa alvorada e o centro experimental de tecnologias - Habitacionais Sustentáveis" (SATTLER, 2009). Para responder aos questionários foram utilizados os seguintes critérios:

a) Não se aplica: quando não foram encontradas informações suficientes para afirmar ou negar alguma das perguntas foi utilizado esta opção que também foi utilizada para situações onde realmente não se aplicava o critério questionado;

b)Sim/não: quando foram encontradas informações suficientes no projeto, extraídas do livro ou relatórios de pesquisas realizadas por integrantes do projeto, para confirmar ou negar a alternativa questionadas.

Figura 04 - Planta Baixa Casa Alvorada

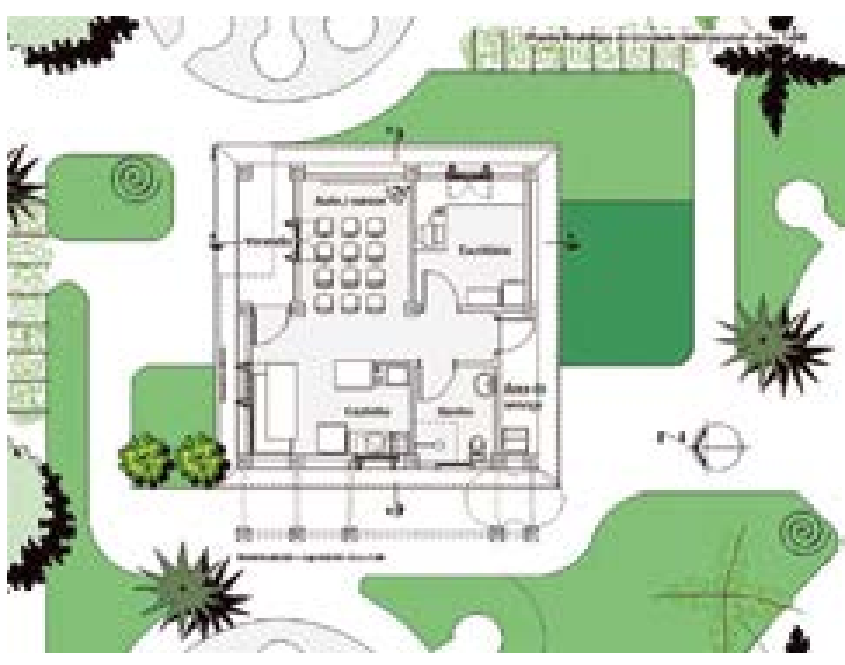

Fonte: Autores

Figura 05 - Perspectiva Casa Alvorada.

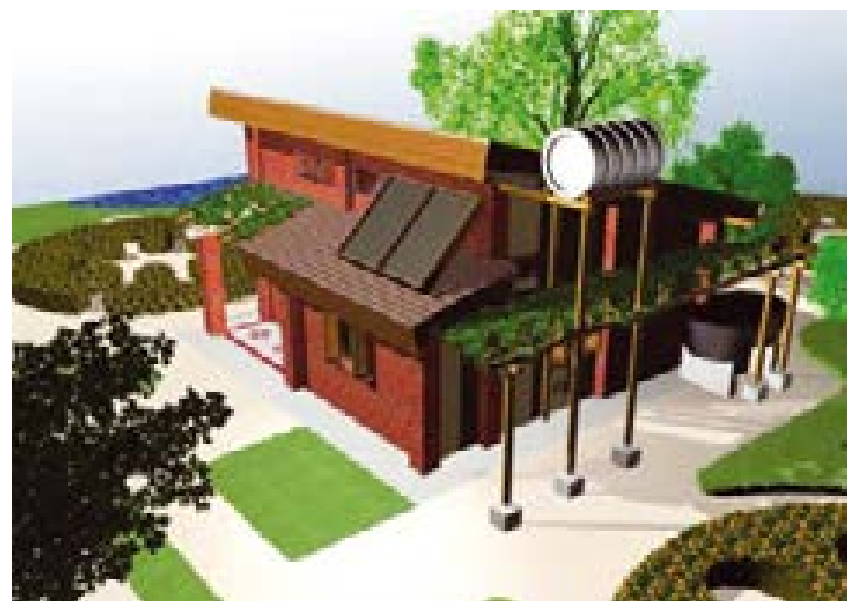

Fonte: Autores 


\subsection{RESULTADOS PARCIAIS}

\subsubsection{Ambiental}

Para análise do aspecto ambiental foram consideradas todas as subcategorias resultando no total de 72,22 pontos como média ponderada dos aspectos. A categoria referente à qualidade interna da habitação, conforto e saúde obteve maior pontuação (80,14 pontos). Já a categoria sobre Consumo de energia e fluxo de massa teve uma pontuação inferior (63,73 pontos), ainda assim, dentro do limite de 50\% (valor mínimo no escopo da metodologia).

Na subcategoria "uso do solo" (A1) o índice obtido foi de 75, contudo são 28 questões apenas neste item, valor que determina 35\% do índice. Ou seja, possui um maior peso na conformação do item enquanto no aspecto conforto eletromagnético, tem apenas dois itens, ainda que apenas um destes pontos fosse conquistado, ele corresponde apenas a $2 \%$ da categoria.

Percebe-se o reflexo da preocupação no projeto sobre diversos aspectos abordados na metodologia, porém, outros itens importantes como segurança estrutural ao fogo uso e operação, ficaram abaixo dos 50\% mínimos do método utilizado.

\subsubsection{Sócio Cultural}

No aspecto sócio cultural, o projeto teve um bom desempenho. Apenas na subcategoria "herança cultural" (E1) obteve pontuação mínima exigida (50\%), contudo foram somente quatro itens ( $50 \%$ do total da subcategoria) respondidos negativamente. Nos aspectos sociais (D) e político institucional ficaram entre $65 \%$ a $80 \%$ o total de respostas positivas. Já na "geração de renda e responsabilidade social" (G) 90,09\% foram atendidas e na "Segurança" (H) $100 \%$ dos quesitos foram atendidos.

Destaca-se neste segmento, que dentro da categoria "G", muitas questões tiveram que ser respondidas Não se aplica (n.a.), uma vez que se tratando de um projeto de pesquisa realizado por uma universidade, as questões de relação trabalhista entre empresa construtora, projetistas, fornecedores de projeto não são aplicáveis à situação, gerando uma leitura errônea do item.

\subsubsection{Econômico}

No aspecto econômico o resultado foi de 70,04, acima da média mínima exigida pelo MASP-HIS. O item viabilidade econômica trouxe o índice para baixo uma vez que muitas questões não foram abordadas no projeto por se tratar de pesquisa.
Figura 06 - Resultado parcial Aspectos Ambientais.

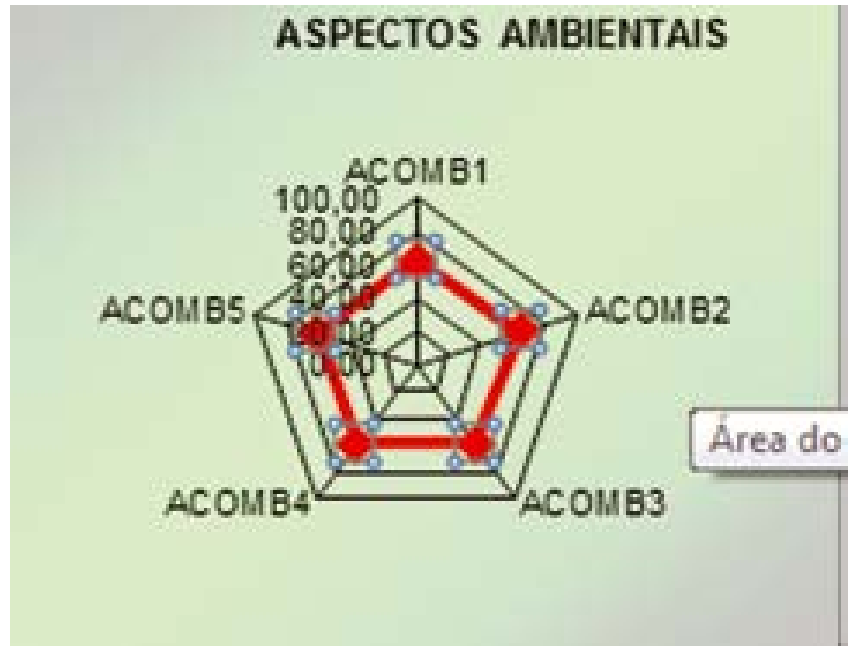

Fonte: Autores

Figura 07 - Resultado parcial Aspectos Socioculturais.

\section{ASPECTOS SOCIOCULTURAIS}

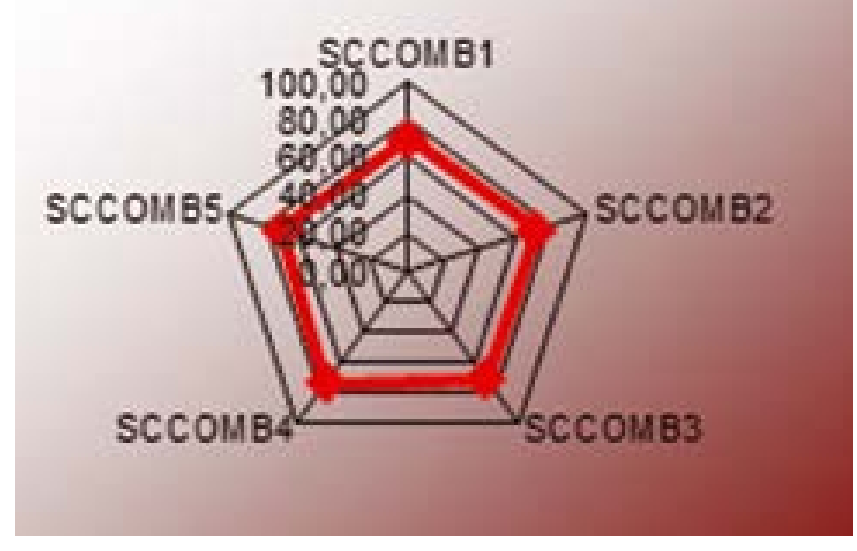

Fonte: Autores

Figura 08 - Resultado parcial Aspectos Econômicos



Fonte: Autores 


\subsection{Resultado final}

$O$ resultado geral foi equilibrado em todas as categorias, apenas combinação cinco do aspecto econômico, resultante das combinações de blocos e argamassas de reboco e assentamento que prejudicou o resultado geral. Ao comparar a avaliação do projeto da Casa Alvorada com a avaliação que Carvalho (2009) realizou de projetos padrão de HIS da prefeitura municipal de Goiânia e da organização não governamental (ONG) Habitat Brasil, há grande disparidade nos resultados. $\mathrm{O}$ projeto Casa Alvorada atingiu em todas as categorias o índice mínimo exigido pelo método (50\%), enquanto o desempenho dos projetos padrão das HIS do estudo de Carvalho (2009) ficam bem abaixo do mínimo exigido. Este melhor desempenho da habitação do NORIE é resultado da preocupação com a sustentabilidade total do projeto.

\section{CONCLUSÕES}

Percebe-se que o método é abrangente, que como metodologia para aplicar em projetos, permite edição posterior dos dados e avaliação das decisões tomadas e suas consequências. Devido à quantidade de informações requeridas pelo programa ele fica extenso de preencher e, além disto, requer um projeto detalhado. É possível que tenha um bom relacionamento com tecnologias Building Information Modeling (BIM) uma vez que as informações são mais acessíveis e inseridas mais cedo que no método tradicional de projeto tornando a avaliação mais realista.

Um fator que chama atenção, contudo, é a disparidade de número de questões em cada subcategoria, o que pode gerar resultados discrepantes e leituras errôneas da sustentabilidade de projeto. As subcategorias com muitas questões podem ter respostas negativas para questões importantes e que não resultarão em maiores prejuízos para o resultado por representarem uma pequena porcentagem do total. Esta é uma questão a ser desenvolvida e melhorada no método.

Para alguns tipos de projeto, como este que não possui a relação patrão-empregado-projetista, tornase praticamente inviável a aplicação, pelo número de questões respondidas negativamente e não aplicáveis e ainda por ter questões passiveis de respostas, porém irreais (uma vez que não existe a relação).

O método, no entanto, abrange um maior número de itens importantes para o cenário de construção civil brasileiro e, especialmente, para habitação de interesse social que os demais selos existentes no mercado. Apesar de número reduzido de questões no aspecto social, ele considera as diversas relações existentes no mercado, o que não é inserido na maioria das avaliações com esta acuidade.

\section{REFERÊNCIAS}

1. CARVALHO, M. T. (2009.). Metodologia para avaliação da sustentabilidade de habitações de interesse social com foco no projeto. 241p. Doutorado (Tese). . Brasília.: Departamento de Engenharia Civil e Ambiental, Universidade de Brasília.

\section{SATTLER, Miguel Aloysio. Habitações de baixo cus-} to mais sustentáveis: a casa Alvorada e o Centro Experimental de tecnologias habitacionais sustentáveis/ Miguel Aloysio Sattler. — Porto Alegre : ANTAC, 2007. — (Coleção Habitare, 8).

3. SILVA, V. G. (2000). Avaliação do desempenho ambiental de edifícios. Revista da Qualidade na Construção. São Paulo., 14-22.

4. SILVA, V. G., \& Agopyan, V. (2004). Avaliação de Edifícios no Brasil: SAltando de Avaliação Ambiental para Avaliação de Sustentabilidade. São Paulo: EPUSP. 